\title{
Collection of breath for hydrogen estimation
}

\author{
ANDREW J GARDINER, MICHAEL J TARLOW, IAN T SUTHERLAND, \\ AND HAROLD G SAMMONS
}

Institute of Child Health, University of Birmingham, and Department of Paediatrics and Department of
Clinical Chemistry, East Birmingham Hospital, Birmingham

SUMMARY The breath hydrogen test is used in gastroenterological investigation, particularly for sugar malabsorption, transit time, and the investigation of small-bowel bacterial overgrowth. Several methods of collecting breath from infants and children for hydrogen assay have been described. Four such techniques (postnasal catheter, nasal prong, Rahn-Otis end-tidal sampler, and a modification of a party toy - the 'Wiggins's blowout') were compared with breath collection using the Haldane-Priestley tube. Multiple sampling of breath from 3 adults was performed after initial lactulose loads to increase breath hydrogen excretion. The variability between the different assay techniques was less than the inherent variability of repeated breath hydrogen assays using the same technique. Each technique is therefore adequate for breath hydrogen collection; we recommend the Rahn-Otis end-tidal sampler in young infants and children, and the Haldane-Priestley tube in older children, since these were most acceptable to the children and their parents.

Hydrogen breath testing has recently been introduced as a research tool in paediatrics. It depends on the excretion of hydrogen in the breath after the oral administration of an appropriate carbohydrate substrate, which is broken down by gut bacteria. The technique is still a research one, and its role has yet to be fully evaluated. However, the use of breath tests, which are painless and non-invasive, appears to have a future in clinical paediatric practice.

The transition of the breath test from a research tool to a diagnostic technique required analysis of breath collection methods. Initially, closed breath collection apparatus was used to measure total breath hydrogen excretion during a defined period, ${ }^{1}$ but Metz et al. ${ }^{2}$ showed close correlation between total hydrogen excretion assessed by this method and interval sampling of end-expiratory air using a Haldane-Priestley tube that had been appropriately modified. The introduction of this latter method greatly improved the practicability of the test.

The problem of collecting breath samples from children has been dealt with in several ways. Wiggins has adapted a children's toy here called the 'Wiggins's blowout' (Fig. 1) for the collection of end-expiratory air. As well as being more attractive to children, it differs from the Haldane-Priestley tube in having a one-way valve fitted which reduces the amount of co-operation required from the patient. It requires some force to inflate it and so is suitable only for children over the age of about 3 years.
Both the Haldane-Priestley and the Wiggins's blowout techniques require active patient co-operation and are therefore unsuitable for infants and small children. Maffei et $a .^{3}{ }^{3}$ described a sampling technique that required passage of a catheter into the postnasal space. Samples collected in this manner were similar in hydrogen content to those collected by the Haldane-Priestley method $(r=0.91)$, even though end-tidal air was sampled rather than end-expiratory air.

The postnasal catheter has been modified ${ }^{4}$ using a nasal prong device inserted into one nostril. We have found that many young children and their parents find both the postnasal catheter and the nasal prong unpleasant. Both share the disadvantage too of needing precise timing to synchronise sample collection with late expiration.

Automatically-timed samples of end-tidal air can be obtained by the small-size Rahn-Otis end-tidal sampler (Warren E Collins Inc., Braintree, Mass.) ${ }^{5}$ fitted with a standard paediatric face mask (Fig. 2). The Rahn-Otis sampler has advantages over other techniques in that it samples end-tidal air which closely parallels alveolar air in composition, ${ }^{\mathbf{5}}$ and is more acceptable to the patient.

The proliferation of breath collection techniques suggested to us that a comparison needed to be made. Not every technique can be used for infants so we chose adults in order to compare the HaldanePriestley tube, the Rahn-Otis end-tidal sampler, and 
(a)
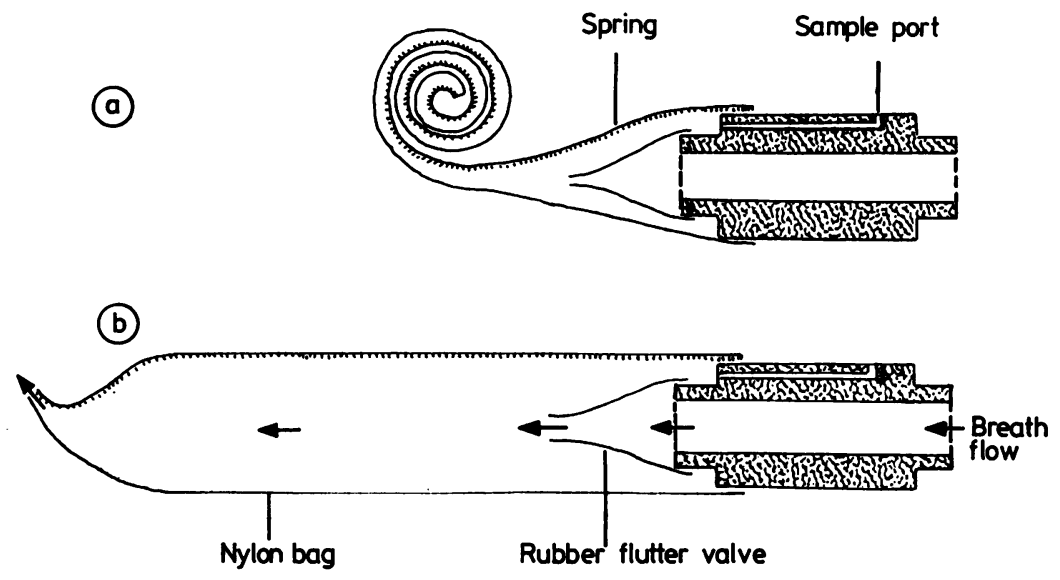

Fig. 1 Wiggins's blowout (a) before inflation, (b) during inflation.

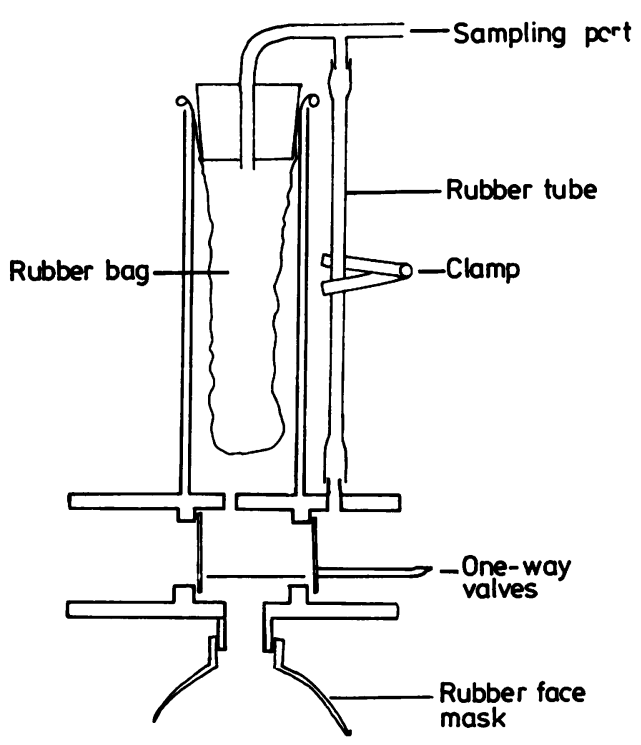

Fig. 2 Rahn-Otis end-tidal sampler.

techniques using the nasal prong and the postnasal catheter. Lactulose $(\beta-1,4$ galactosido-fructose) (Duphar Laboratories, Southampton) was administered beforehand in order to produce measurable quantities of breath hydrogen.

\section{Methods}

Three healthy adults were given lactulose $20 \mathrm{~g}$, and triplicate breath samples were obtained at varying times thereafter by each method in rapid random sequence. No sampling sequence took more than 4 minutes to complete.
Previously described techniques were used for sampling by Haldane-Priestley tube, ${ }^{2}$ the postnasal catheter, ${ }^{3}$ and the nasal prong. ${ }^{4}$ Each subject was instructed to blow hard from an end-expiratory position into a modified Wiggins's blowout (Fig. 1). The Rahn-Otis sampler was fitted with a mouthpiece, and the nose clamped. Two samples, each of $15 \mathrm{ml}$ volume, were collected and mixed in the same syringe, with the subject breathing normally. For each technique the dead space of the system was allowed to flush several times with expired air before sample collection.

$30 \mathrm{ml}$ samples were collected into $50 \mathrm{ml}$ capacity polypropylene syringes (Becton Dickinson, Middlesex) fitted with 3-way taps (AHS, Belgium) and analysed immediately by gas-solid chromatography using a katharometer detector. Analytical techniques are described elsewhere (A J Gardiner et al., in preparation).

\section{Results}

Thirteen sets of triplicate samples were obtained, with hydrogen concentrations ranging from 0 to 207 parts per million. Three samples were accidentally lost.

The Haldane-Priestley technique was used as the standard for comparison with the other techniques. Correlation coefficients for hydrogen concentration in parts per million were calculated between each technique and the Haldane-Priestley tube by linear regression both for individual pairs of samples and for the means of the triplicate samples (Table).

Analysis of variance showed that $68 \%$ of the total variance arose within groups (that is, within groups of values obtained by each collecting technique) and 
Table Comparison of the Haldane-Priestley tube with other methods of collecting breath

\begin{tabular}{|c|c|c|c|c|}
\hline $\begin{array}{l}\text { Haldane-Priestley } \\
\text { tube }\end{array}$ & $\begin{array}{l}\text { Rahn-Otis } \\
\text { end-tidal } \\
\text { sampler }\end{array}$ & $\begin{array}{l}\text { Postnasal } \\
\text { catheter }\end{array}$ & $\begin{array}{l}\text { Nasal } \\
\text { prong }\end{array}$ & $\begin{array}{l}\text { Wiggins's } \\
\text { blowout }\end{array}$ \\
\hline $\begin{array}{l}\text { Individual values } \\
\text { Correlation coefficient } \\
\mathrm{n}\end{array}$ & $\begin{array}{l}0.91 \\
37\end{array}$ & $\underset{36}{0.89}$ & $\underset{36}{0.85}$ & $\begin{array}{l}0 \cdot 87 \\
37\end{array}$ \\
\hline $\begin{array}{l}\text { Means of } 3 \text { values } \\
\text { Correlation coefficient } \\
\text { n }\end{array}$ & $\begin{array}{l}0.95 \\
13\end{array}$ & ${ }_{13}^{0.94}$ & 13 & $\begin{array}{l}0.97 \\
13\end{array}$ \\
\hline
\end{tabular}

the remaining $32 \%$ of variance arose from differences between groups (collecting techniques). Thus there was considerable variation from sample to sample regardless of the collection technique, and no single technique was clearly superior.

\section{Discussion}

The composition of alveolar air varies during the respiratory cycle. ${ }^{5}$ Alveolar hydrogen concentration may also vary, requiring standardisation of the phase of the respiratory cycle from which the sample is obtained. This is achieved by means of the RahnOtis end-tidal sampler. However, the use of this sampler in very small infants and newborn babies is limited by considerations of the dead space of the apparatus (nominally $8 \mathrm{ml}$ plus mask $2-10 \mathrm{ml}$ ) in relation to the patient's tidal volume.

No technique showed clear superiority over the Haldane-Priestley tube, although all specimens correlated quite closely for hydrogen content. For reasons of patient acceptability and for theoretical considerations, we now use the Rahn-Otis end-tidal sampler for breath collection in young children and infants with predicted tidal volumes over $20 \mathrm{ml}$. We use the Haldane-Priestley tube for older children who are actively able to co-operate.

We thank Dr Hugh Wiggins of Dunn Nutrition Laboratories, Cambridge, for information about the device that bears his name, Professor Charlotte Anderson for advice throughout the study, and for permission to include her patients, Mr Roger Gouch of the Department of Respiratory Physiology, East Birmingham Hospital, who provided advice on breath collection techniques, and Mrs B Tennant and Mrs P Jackson who prepared the manuscript.

\section{References}

1 Levitt M D. Production and excretion of hydrogen gas in man. $N$ Engl J Med $1969 ; 281$ : 122-7.

2 Metz G, Gassull M A, Leeds A R, Blendis L M, Jenkins D J A. A simple method of measuring breath hydrogen in carbohydrate malabsorption by end-expiratory samples. Clin Sci Mol Med 1976; 50: 237-40.

3 Maffei H V L, Metz G L, Jenkins D J A. Hydrogen breath test: adaptation of a simple technique to infants and children. Lancet 1976; i: 1110-1.

4 Perman J A, Barr R G, Watkins J B. Sucrose malabsorption in children: non-invasive diagnosis by interval breath hydrogen determination. J Pediatr 1978; 93: 17-22.

5 Otis A B. Quantitative relationship in steady-state gas exchange. In: Fenn W O, Rahn H, eds. Handbook of physiology. Vol. 1, section 3: Respiration. Washington DC: American Physiological Society, 1964: 696.

Correspondence to Dr M J Tarlow, Department of Paediatrics, East Birmingham Hospital, Bordesley Green East, Birmingham B9 5ST.

Received 26 October 1979 